\title{
CYCLES IN THE GLOBAL MILK MARKET
}

\author{
Jakub Olipra ${ }^{\bowtie}$ \\ Warsaw School of Economics, Poland
}

\begin{abstract}
The main purpose of this research is to analyze milk market cycles in major dairy exporting regions (European Union, New Zealand and United States). The research was based on peak-to-peak analysis of seasonally adjusted farmgate milk prices recorded from January 2001 to April 2018. The results indicate that in all regions covered by this analysis, milk cycles are uneven and irregularly interspersed. This above shows that the length of milk cycles is determined not only by the breeding cycle of cows, as it is commonly believed, but also by numerous political, institutional, economic and environmental factors. Furthermore, the magnitude of milk cycles in the regions considered generally tends to increase which suggests their growing importance in determining farmgate milk prices. Also, milk market cycles followed by major dairy exporters are strongly correlated which indicate the presence of a common global milk market cycle. Research findings show that forecasting farmgate milk prices requires considering much more factors than previously recognized. Moreover, the results of the analysis align current research efforts taken in this area which provide ambiguous conclusions.
\end{abstract}

Keywords: milk prices, milk market cycles, forecasting, dairy market

\section{INTRODUCTION}

Dairy markets around the world have been strictly regulated for many years (OECD, 2005). Internal measures like public interventions and export subsidies stabilized markets and reduced milk price volatility (Keane and O’Connor, 2009). As a consequence, milk prices charged by major dairy exporters used to oscillate around long term trends, with seasonality as the only driver of price volatility. Together with the deregulation of national dairy markets, milk prices became much more volatile (see Fig. 1). As a result, farmers became exposed to swings in profitability which induced the phenomenon of cyclicality to milk markets.

Cyclicality is a common feature of agricultural commodity markets. Regardless of the price they can obtain, farmers have limited ability to significantly increase supply in short term. This is due to lags in agricultural production resulting from its biological nature, such as the delay between planting and harvest or breeding and maturity of the offspring; it varies depending on agricultural production type. Farmers are also reluctant to reduce supply in the short term due to the sunk cost of production they have already incurred. Therefore, increases in demand are usually accompanied by periods of supply shortages which boost prices significantly above the cost of production. Growing profitability encourages farmers to invest in expanding supply. Uncoordinated actions of many farmers often generate a wave of increased supply with a delay specific to each type of agricultural production. Meanwhile, demand eases due to high prices. As a consequence, higher supply appears usually in periods of demand slowdown, leading to oversupply and a drop in prices. As farmers are reluctant to reduce supply, prices continue to fall below the production costs which finally forces farmers to adjust the level of supply. Afterwards, low prices boost demand, and the loop restarts.

$凶$ Jakub Olipra, Msc, Collegium of Economic Analysis, Warsaw School of Economics, Madalińskiego 6/8 St., 02-513 Warsaw, Poland, e-mail: jakub.olipra@gmail.com, https://orcid.org/0000-0001-92 16-6056 


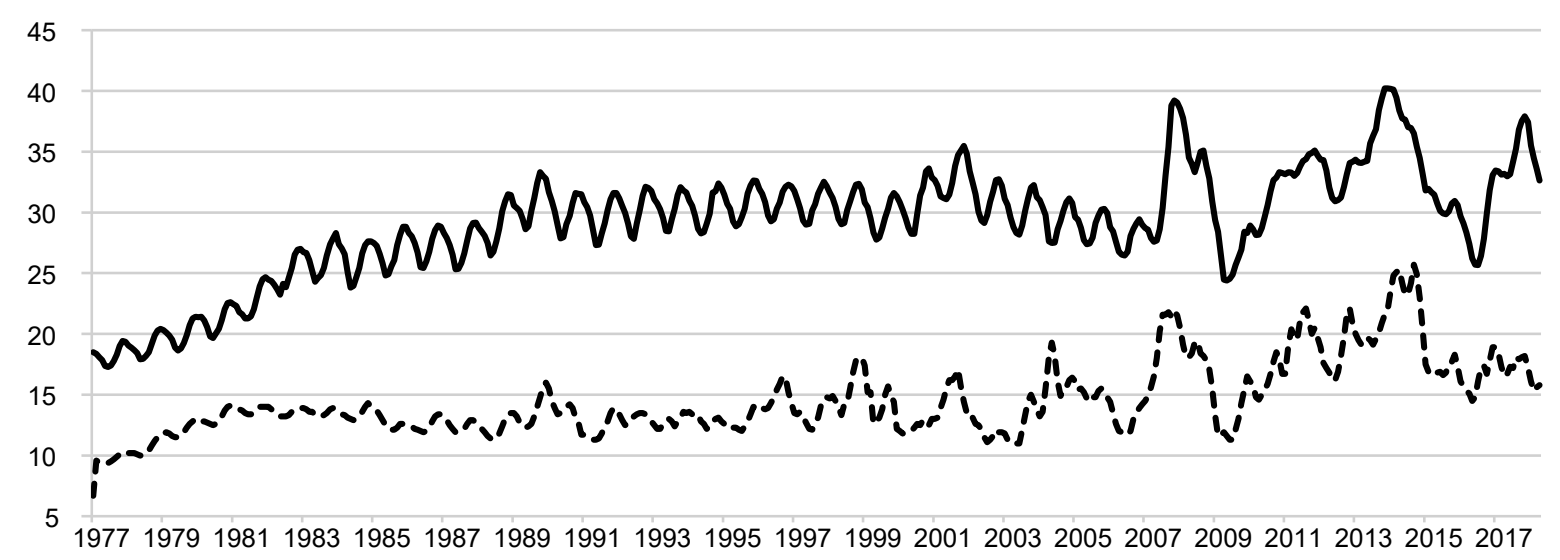

EU (EUR per $100 \mathrm{~kg})$

- - - US (USD per $100 \mathrm{~kg}$ )

Fig. 1. Monthly farmgate milk prices in the US and EU Source: own calculations.

\section{LITERATURE REVIEW}

Although the phenomenon of cyclicality in agricultural markets is not new to researchers, the literature on cycles in milk markets is scarce. Moreover, findings from previous research are sometimes contradictory, especially when it comes to the duration and predictability of milk market cycles. All these issues may result from the relatively short time series of milk prices which were found to include a strong cyclical component. Therefore, further research needs to be carried out in this area. Hence, the first aim of this study is to test the hypothesis if the duration of milk market cycles is constant or changes over time. The second aim of this study is to investigate the correlation between the cycles in the main dairy export regions (in the New Zealand, EU and US) and to answer the question if the global milk market follows a common cycle. Findings from this research may help dairy sector professionals in formulating their price expectations more precisely. What is more, the conclusions provide important assumptions for further research on milk market cycles.

The paper is organized as follows. Section 2 discusses the literature in the field of milk market cycles. Section 3 presents data collection methods used in the research. Section 4 discusses the statistical methods employed in the research. Section 5 shows estimation results. Section 6 presents the concluding remarks.
While the literature mostly focuses on cattle cycles, research on milk market cycles is scarce. Although cattle and milk cycles differ significantly, the analysis of the former may serve as a good starting point for the discussion on milk market cycles. Cattle are both investment and consumption goods (Breimyer, 1955; Jarvis, 1974; Rosen et al., 1994; Mundlak and Huang, 1996; Aaland, 2004). Therefore, current breeding and consumption decisions have important implications for future stocks. Low fertility rates of cows result in substantial lags between the current breeding decision and the effect it has on the herd size and demographic structure. As a consequence, the herd size and structure respond cyclically to exogenous shocks in demand for beef and production costs (Mundlak and Huang, 1996; Mathews et al. 1999; Aaland, 2004; Stockton and Tassell, 2007). There is a consensus that the duration of cattle cycles is about 10 to 12 years (Franzmann, 1971; Mundlak and Huang, 1996; Mathews et al. 1999; Aaland, 2004), and is similar in different countries (Mundlak and Huang, 1996). This underlines the dominance of biological factors as their determinants.

The issue of milk market cycles was investigated by Hunt and Kern (2012). They believe that with the growing integration of the US and global milk market, milk cycles in the US became much less predictable. First of 
all, global demand is driven by increasingly volatile factors like growth in developing countries, dietary shifts, product contamination, shifting regulation and currency strength of import regions. Secondly, the global supply base cannot be considered homogenous as farmers in different regions have different breakeven points. Thus, aligning the global milk supply with low or high price levels is a complex and irregular process. Therefore, the highs and lows are much less regularly interspersed than it was observed in 1990-2005.

Milk market cycles were also investigated into by Nicholson and Stephenson (2014). Using the state-space model, they decomposed the US all-milk price recorded in 1996-2014 into a trend and seasonal and cyclical components. Their research also included feed costs as an exogenous regressor to assess the nature of cyclical behavior of milk prices in the US. They concluded that a large-amplitude stochastic cycle with a period of 3.3 years was the predominant source of variation in the US all-milk price over the study period. Cycle duration is consistent with the breeding cycle of cows: three years between the decision to breed heifers and the offspring being able to produce milk. Moreover, their research findings suggest that changes in feed prices do not cause cycles although they may have some influence on their magnitude and timing.

The same method as in Nicholson and Stephenson (2014) was employed by Bergmann et al. (2015) who decomposed the EU, German and Irish farmgate milk prices into a trend and seasonal and cyclical components. Their analysis was conducted for two periods: 1995-2004 (prior to the Common Agricultural Policy, CAP, reform) and 2004-2013 (after the CAP reform). They showed that cycle duration in the first period varied in the range from 43 months in Ireland and 47 months in Germany to 55 months as the EU average. In the second period, cycle duration is almost identical for all three series, with 37 months as the EU average, 38 months in Germany and 39 months in Ireland. This is consistent with the findings by Nicholson and Stephenson (2014). Moreover, as shown in their research, the significance of the cycle component in determining milk prices in the EU increased considerably in the second sample. The authors state that one explanation for the convergence of cycle duration across EU countries and the growing impact of the cyclical component on milk prices could be the market-oriented reforms of the CAP.
Therefore, there is a discrepancy in the literature. Hunt and Kern (2012) consider that together with the globalization of dairy the market, milk market cycles become much more irregular. Meanwhile, Nicholson and Stephenson (2014) and Bergmann et al. (2015) assume that the duration of the cycle is more or less constant over time, and is mainly determined by the biological nature of milk production, namely the breeding cycle of cows.

\section{DATA COLLECTION}

The analysis was based on monthly data on farmgate milk prices for the US, EU and New Zealand. The selection of the regions was motivated by their significance in the global milk market. New Zealand, EU and the US represent almost $69 \%$ of global exports of dairy products expressed in milk equivalent (FAO, 2018). The study period is from January 2001 to April 2018 (the longest period where all time series are available). The time series were obtained from a variety of sources. Average farmgate milk prices in the EU were collected from the Milk Market Observatory. Prices for New Zealand come from the LTO Nederland database. The US farmgate milk prices were obtained from USDA Statistics and Market Information System. All prices used in the research are nominated in euro. Table 1 reports the descriptive statistics for the time series used in the research. Figure 2 shows the historical price relationships.

Table 1. Descriptive statistics for farmgate milk prices (EUR per $100 \mathrm{~kg}$ )

\begin{tabular}{lrrrr}
\hline & Min & Median & Mean & Max \\
\hline EU & 24.39 & 31.47 & 31.77 & 40.21 \\
New Zealand & 13.01 & 23.59 & 23.88 & 41.04 \\
US & 11.00 & 19.63 & 20.81 & 34.94 \\
\hline
\end{tabular}

Source: own calculations. 


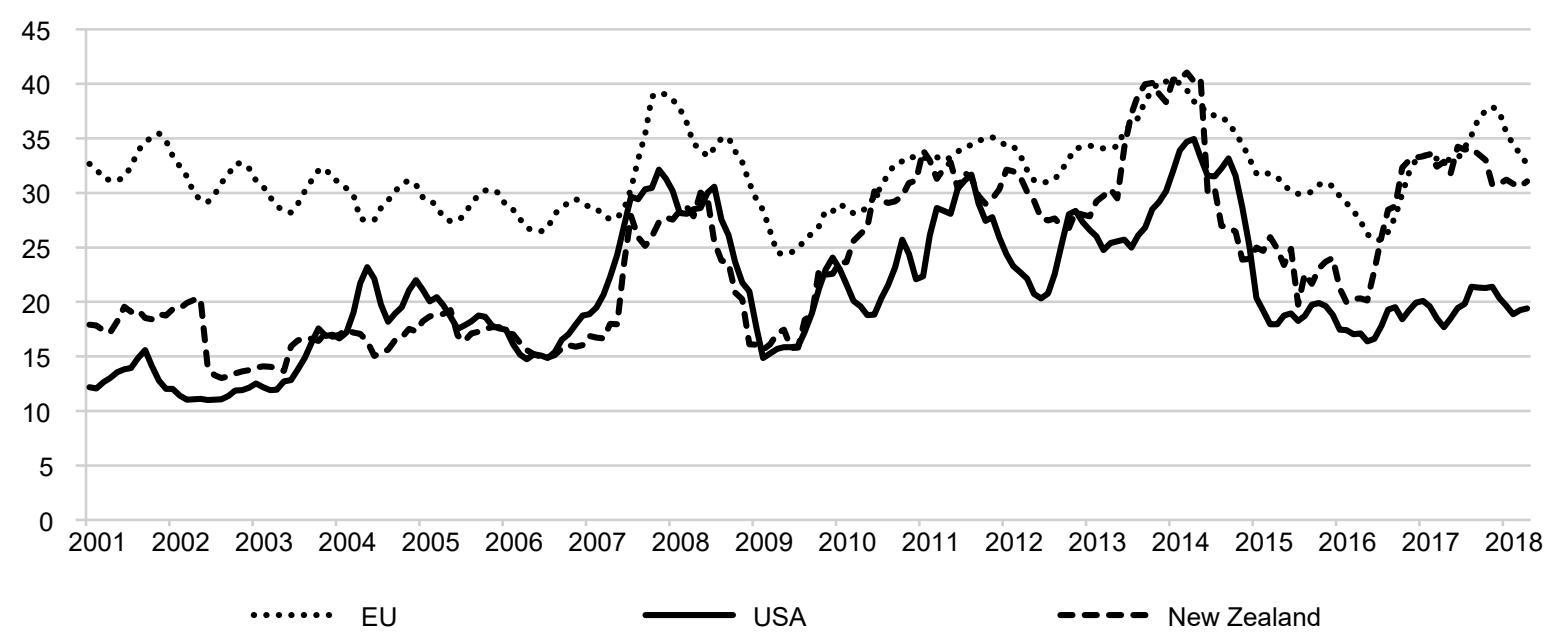

Fig. 2. Farmgate milk prices in the US, EU and New Zealand (EUR per $100 \mathrm{~kg}$ ) Source: own calculations.

\section{METHODOLOGY}

In today's literature related to milk market cycles, the main approach are state-space models (Harvey, 1989; Hamilton, 1994; Durbin and Koopman, 2001), as employed by Nicholson and Stephenson (2014) and Bergmann et al (2015). Their main advantage is the ability to explicitly capture the underlying system structure. Meanwhile, spectral analysis filters, such as those used by Hodrick and Prescott (1997), Christiano and Fitzgerald (1999) or Baxter and King (1999), enable only a statistical decomposition of time series. Other statistical methods like peak-to-peak (or trough-to-trough) analysis or exponential smoothing enable only to infer on the volatility of time series. Nevertheless, there are some significant limitations of the approach based on statespace models. Firstly, state-space models assume that cycles have a constant frequency and, therefore, a constant period. It is contradictory to findings by Hunt and Kern (2012) that milk cycles are irregular and by Bergmann et al. (2015) that milk cycles are getting shorter. Secondly, the stochasticity of the cycle in state-space models is achieved by adding the disturbance component which is uncorrelated and independent. In the case of milk market cycles, that assumption may not be valid due to the following issues. As partially mentioned by Hunt and Kern (2012), milk market cycles are driven not only by biological factors, such as the breeding cycle of cows, but also by economic factors which grow in importance. Some of them may have a structural impact on dairy markets, and therefore cannot be treated only as random disturbance. Moreover, if milk market cycles tend to become shorter, the disturbance component used in state-space models may not be uncorrelated and independent. Hence, considering the above limitations of state-space models, the peak-to-peak analysis employed by Hunt and Kern (2012) seems to be a more suitable approach. Therefore, this study relied on the peak-to-peak method used by Hunt and Kern (2012). However, it was partially modified through a prior seasonal adjustment of the time series studied. The seasonal adjustment was based on the multiplicative version of the Census X-12 procedure (US Census Bureau, 2011). Upon removal of seasonal fluctuations, the time series was only composed of a trend and cyclical and random disturbance components which improved the clarity of inference. In the last step of research, the moving correlation between seasonally adjusted milk prices in the EU, US and New Zealand were computed in order to investigate if there is a common cycle in the global milk market.

\section{RESULTS}

Figure 3 shows milk market cycles in the period from January 2001 to April 2018. The study period witnessed 4 full milk market cycles in the US, and 3 full cycles both in the EU and New Zealand. The average length of milk cycles (from peak to peak) is similar in 

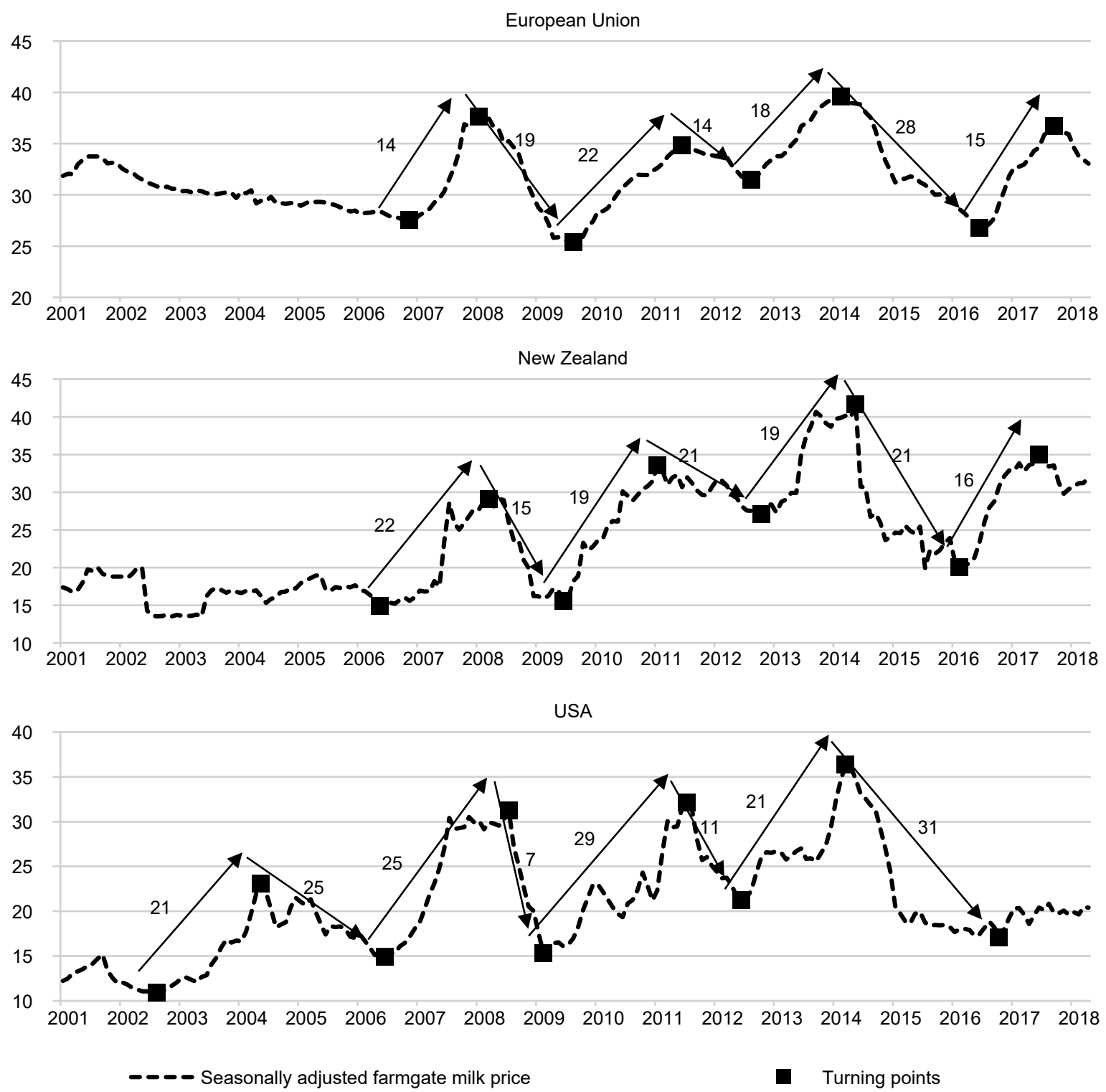

Fig. 3. Milk cycles against the backdrop of seasonally adjusted farmgate milk prices in the EU, New Zealand and the US (numbers above the arrows represent the length of the particular phases of milk cycles expressed in months) Source: own calculations.

different regions, with 39 months in EU and New Zealand and 37 months in the US. Nevertheless, inference based on the average duration of milk market cycles may lead to wrong conclusions, as the cycles under study demonstrate a relatively strong dispersion. The shortest milk market cycles (32 months) were recorded in the EU and New Zealand while the longest cycle occurred in the US, reaching 50 months. It suggests that milk market cycles are not always consistent with the breeding cycle of cows and that other non-biological factors exist which determine their duration. For example, in 2011-2012 the decreasing phase of milk market cycle in all regions analyzed was shortened by adverse weather conditions in New Zealand and speculative demand in China, while in 2014-2015 it was extended by the Russian embargo and the abolition of milk quotas in the EU. What is especially noteworthy, there is no evidence that cycles are getting shorter. Moreover, 

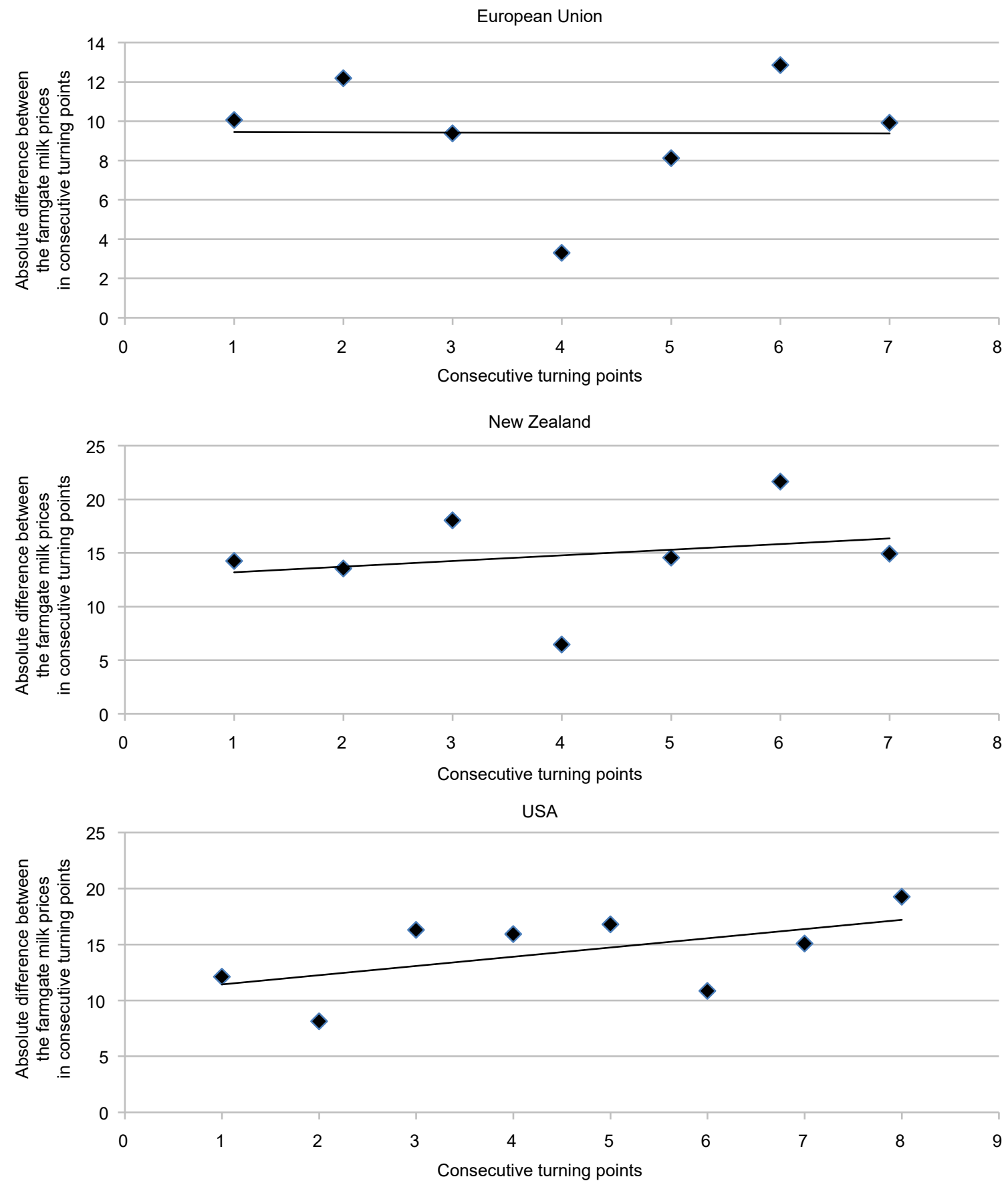

Fig. 4. Magnitude of milk cycles in EU, New Zealand and the US Source: own calculations.

in the study period, milk market cycles were generally asymmetric. Nevertheless, it is impossible to explicitly state which phase of the cycle tends to become longer because particular phases were irregular. Furthermore, the amplitude of milk cycles in the study period was generally increasing (see Fig. 4). It suggests that cyclical components have a growing role in determining farmgate milk prices. 


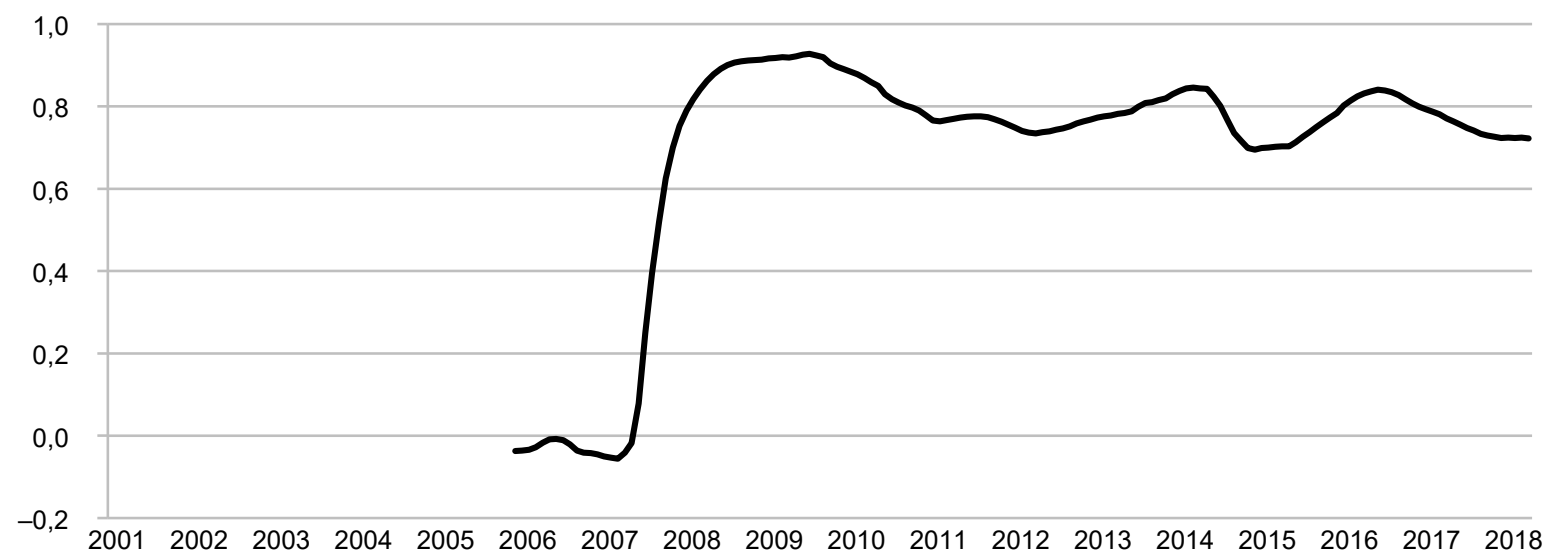

Fig. 5. Average 60-month moving correlation between farmagate milk prices in the US, EU and New Zealand Source: own calculations.

As shown in Fig. 5, in early 2007, there was a significant increase in correlation between farmgate milk prices in the US, New Zealand and the EU, and it remained at an elevated level. It suggests that milk market cycles in major dairy exporting regions are strongly interdependent, and a common cycle exists in the global milk market. However, based on Figure 3, it can be stated that none of the regions analyzed have leading properties in forecasting the turning points of the global milk market cycle.

\section{CONCLUDING REMARIKS}

The results of this research support the findings by Hunt and Kern (2012) who claim that milk market cycles became uneven and much less predictable, and indicate that this conclusion is true not only for the US but also for the EU and New Zealand. Therefore, the above is contradictory to findings by Nicholson and Stephenson (2014) and Bergmann et al. (2015) that the length of the milk market cycle is more or less constant over time and is mainly determined by the breeding cycle of cows. The analysis of the last milk cycles suggest that political, institutional, economical and environmental factors play an increasingly important role in determining the duration of cycles. Furthermore, the magnitude of milk cycles in regions analyzed tends to increase which suggest the growing importance of cycles in determining farmgate milk prices. Also, milk market cycles followed by major dairy exporters are strongly correlated which indicate the presence of a common global milk market cycle. Therefore, due to the fact that the global supply base cannot be considered homogeneous (because farmers in different regions have different breakeven points), the adjustment of the world milk supply to low or high price levels is much more complex and irregular. Hence, research findings show that forecasting farmgate milk prices requires considering much more factors than previously recognized.

\section{SOURCE OF FINANCING}

Article financed by the author.

\section{REFERENCES}

Aadland, D. (2004). Cattle Cycles, Heterogeneous Expectations and the Age Distribution of Capital. J. Econ. Dyn. Cont., 28, 1977-2002. DOI: 10.1016/j.jedc.2003.08.003

Baxter, M., King, R. G. (1999). Measuring business cycles: approximate band-pass filters for economic time series. Rev. Econ. Stat., 81(4), 575-593. DOI: 10.1162/0034653995 58454

Bergmann, D., O’Connor, D., Thümmel A. (2015). Seasonal and cyclical behaviour of farm gate milk prices. Brit. Food J., 117(12), 2899-2913. DOI: 10.1108/BFJ-08-2014-0294

Breimyer, H.F. (1955). Observations on the Cattle Cycle. Agric. Econ. Res., 7, 1-11.

U.S. Census Bureau (2011). X-12-ARIMA Reference Manual, U.S. Census Bureau, Washington DC.

Christiano, L. J., Fitzgerald, T. J. (2003). The band pass filter. Int. Econ. Rev., 44, 435-465. DOI: 10.1111/1468-2354. t01-1-00076 
DC AGRI (2018). Data on EU farmgate milk prices, EU Milk Market Observatory. Retrieved from: https://ec.europa.eu/ agriculture/market-observatory/milk

Durbin, J., Koopman, S. J. (2001). Time Series Analysis by State Space Methods. Oxford: Oxford University Press.

FAO (Food and Agriculture Organization) (2018). Dairy Market Review. Rome. Retrieved from: http://www.fao.org/3/ I9210EN/i9210en.pdf

Franzmann, J.R. (1971). Cattle Cycles Revisited. South. J. Agric. Econ., 3, 69-76. DOI: 10.1017/S0081305200010153

Hamilton, J. D. (1994). Time Series Analysis. Princeton: Princeton University Press.

Harvey, A. C. (1989). Time Series Analysis. Forecasting, Structural Time Series Models and the Kalman Filter. Cambridge: Cambridge University Press.

Hodrick, R. J., Prescott, E. C. (1997). Postwar US business cycles: an empirical investigation. J. Money Cred. Bank., 29(1), 1-16. DOI: $10.2307 / 2953682$

Hunt, T., Kern, M. (2012). The end of the old US dairy price cycle, Rabobank Industry Note, 355. Utrecht: Rabobank International.

Jarvis, L. S. (1974). Cattle as Capital Goods and Ranchers as Portfolio Managers: An Application to the Argentine Cattle Sector. J. Polit. Econ., 82, 489-520.

Keane, M., O'Connor, D. (2009). Price Volatility in the EU Dairy Industry: Causes, Consequences and Coping Mechanisms. Report prepared for the European Dairy Association.
LTO Nederland (2018). International Milk Price Reviews. Retrieved from: http://www.milkprices.nl/

Mathews, K. H., Hahn, W. F., Nelson, K. E., Duewer, L. A., Gustafson, R. A. (1999). U.S. Beef Industry: Cattle Cycles, Price Spreads, and Packer Concentration. Techn. Bull. 33583, United States Department of Agriculture, Economic Research Service.

Mundlak, Y., Huang, H. (1996). International Comparisons of Cattle Cycles. Am. J. Agric. Econ., 78, 855-868. DOI: $10.2307 / 1243843$

Nicholson, C. F., Stephenson., M. W. (2014). Milk price cycles in the US dairy supply chain and their management implications. Agribusiness, 31(4), 507-520. DOI: 10.1002/ agr.21416

OECD (2005). Dairy Policy Reform and Trade Liberalization. Paris, OECD Publications.

Rosen, S., Murphy K. M., Scheinkman J. A. (1994). Cattle Cycles. J. Polit. Econ., 102, 468-492. DOI: 10.1086/261942

Stockton, M. C., Van Tassell, L. W. (2007). The Cattle Price Cycle: An Exploration in Simulation. Proceedings of the NCCC-134 Conference on Applied Commodity Price Analysis, Forecasting, and Market Risk Management. Chicago, Illinois.

U.S. Department of Agriculture (2018). Agricultural Prices, Statistics and Market Information System. Retrieved from: http://usda.mannlib.cornell.edu/MannUsda/viewDocu mentInfo.do?documentID $=1002$ 